\section{Mechanisms of Weed Suppression in Cover Crop-based Production Systems}

\author{
Nancy G. Creamer ${ }^{1}$, Mark A. Bennett ${ }^{2}$, Benjamin R. Stinner ${ }^{3}$, \\ John Cardina ${ }^{4}$, and Emilie E. Regnier ${ }^{2}$ \\ Department of Horticulture and Crop Science, The Ohio State University, \\ 2021 Coffey Road, Columbus, OH 43210
}

\section{Additional index words. allelopathy, Secale cereale, Hordeum vulgare, Trifolium incarnatum, Vicia villosa, Solanum ptycanthum, Setaria glauca}

\begin{abstract}
Field and laboratory studies were conducted to investigate the mechanisms of weed suppression by cover crops. High-performance liquid chromatograph analysis and a seed germination bioassay demonstrated that rye (Secale cereale $\mathrm{L}$.) can be leached of its allelochemicals, redried, and used as an inert control for separating physical suppression from other types of interference. In a field study, rye, crimson clover (Trifolium incarnatum L.), hairy vetch (Vicia villosa Roth.), barley (Hordeum vulgare L.), and a mixture of the four species suppressed the emergence of eastern black nightshade (Solanum ptycanthum Dun.). Crimson clover inhibited the emergence of eastern black nightshade beyond what could be attributed to physical suppression alone. The emergence of yellow foxtail [Setaria glauca (L.) Beauv.] was inhibited by rye and barley but not by the other cover crops or the cover crop mixture.
\end{abstract}

Winter annual cover crops can be used in vegetable and agronomic crop conservation tillage systems to reduce soil erosion (Flach, 1990), leaching losses of fertilizers, and inputs of chemical fertilizer and pesticides. Researchers have used cover crops of wheat (Triticum aestivum L.) (Worsham, 1991), barley (Overland, 1966), rye (Barnes and Putnam, 1986), sorghum-sudangrass (Sorghum sudanense) (Weston et al., 1989), crimson clover, hairy vetch (Teasdale, 1993; White et al., 1989), and other cover crops to suppress weeds.

Cover crop residues remaining on the soil surface can physically modify seed germination by altering the seed environment (changes in light availability, soil temperatures, and soil moistures) and through other types of interference, primarily allelopathy. Allelopathy has been defined as "any direct or indirect harmful effect produced in one plant through toxic

Received for publication 19 July 1995 . Accepted for publication 8 Jan. 1996. Journal article no. 189-95. The Ohio Agricultural Research and Development Center (OARDC), The Ohio State Univ. (OSU). This paper is a portion of a thesis submitted by Nancy Creamer in partial fulfillment of $\mathrm{PhD}$ requirements at The Ohio State Univ. Mention of a trademark, proprietary product, or vendor does not constitute a product guarantee or warranty by The Ohio State Univ. and does not imply its approval to the exclusion of other products or vendors. Research supported in part by state and federal funds appropriated to OSU-OARDC. The cost of publishing this paper was defrayed in part by the payment of page charges. Under postal regulations, this paper therefore must be hereby marked advertisement solely to indicate this fact.

${ }^{1}$ Former Graduate Research Assistant. Currently, Assistant Professor, Horticultural Science Dept., North Carolina State Univ., Vernon G. James Research and Extension Center, 207 Research Station Rd., Plymouth, NC 27962.

${ }^{2}$ Associate Professor.

${ }^{3}$ Associate Professor, Dept. of Entomology.

${ }^{4}$ Research Scientist. chemicals released into the environment by another" (Rice, 1974). This definition has been broadened to include chemicals produced by actinomycetes, algae, fungi, or other microbes that may associate with the plants in the rhizosphere (Putnam, 1988).

Many studies of allelopathic residues have been conducted with rye because of its substantial biomass production and apparent phytotoxicity. Putnam and DeFrank (1983) reported that rye residue reduced the emergence of common ragweed (Ambrosia artemisiifolia L.) by $43 \%$, green foxtail [Setaria viridis (L.) Beauv.] by $80 \%$, redroot pigweed (Amaranthus

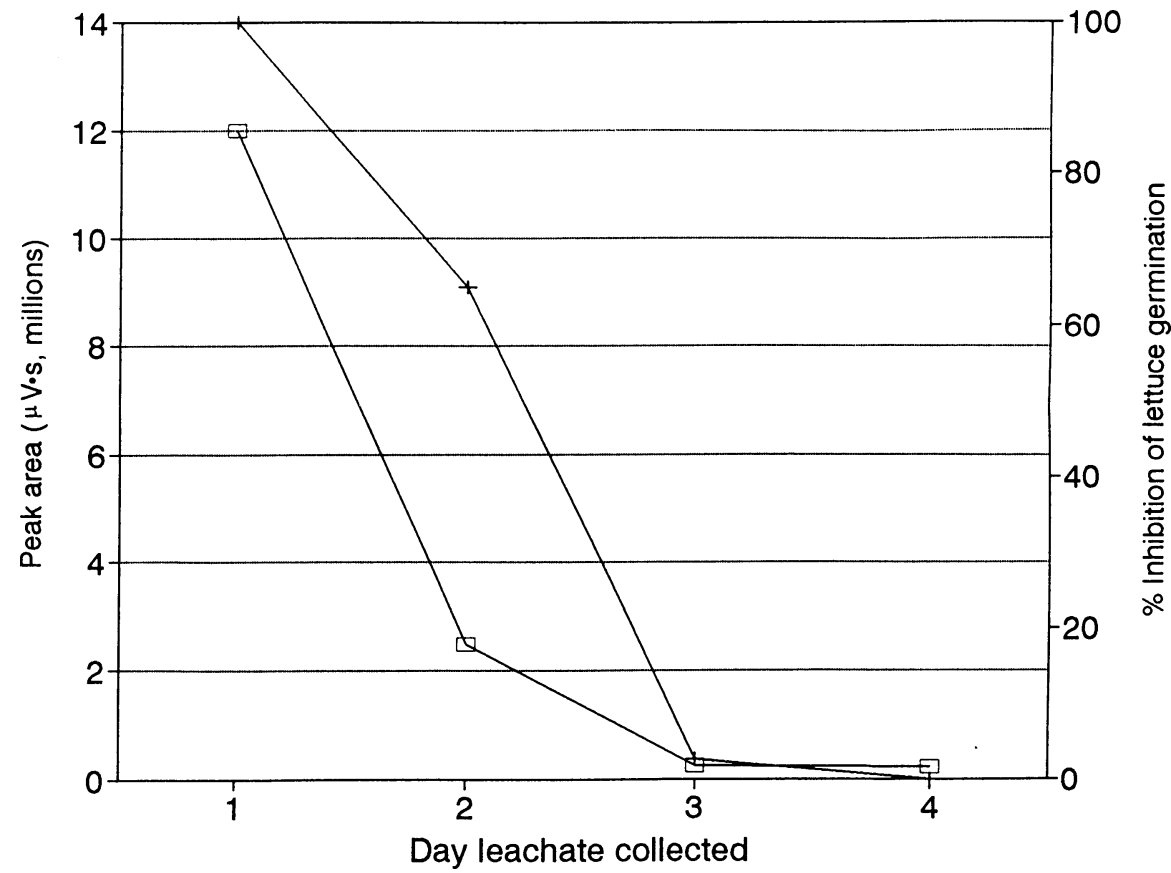

Fig. 1. (ㄱ) High-performance liquid chromatography peak area $(\mu \mathrm{V} \cdot \mathrm{s})$ at $280 \mathrm{~nm}$ for leachates during four consecutive days of extraction from rye residue. Also plotted is (--+--) percent inhibition of lettuce germination with the four leachates. observed under these conditions may not oc- retroflexus L.) by $95 \%$, and common purslane (Portulaca olearacea L.) by $100 \%$, but it had no effect on the emergence of yellow foxtail [Setaria glauca (L.) Beauv.]. Shilling et al. (1985) reported that a surface mulch of desiccated rye in a no-till system reduced aboveground biomass of common lambsquarters (Chenopodium album L.) by $99 \%$, redroot pigweed by $96 \%$, and common ragweed by $92 \%$ compared to an unmulched tilled control. Nine chemicals believed to be active allelochemicals in rye, including vanillic, ferulic, phenylacetic, 4-phenylbutyric, $p$ coumaric, $p$-hydoxybenzoic, salicylic, and $o$ coumaric acids and salicylaldehyde, have been identified (Chou and Patrick, 1976). Shilling et al. (1985) found that $\beta$-phenyllacetic acid and $\beta$-hydroxybutyric acid in rye residue inhibited germination of common lambsquarters $20 \%$ and redroot pigweed $60 \%$. Two hydroxamic acids [2,4-dihydroxy-1,4 $(2 \mathrm{H})$ benzoxazin-3-one (DIBOA) and 2(3H)benzoxazolinone (BOA)] also were isolated from rye and were phytotoxic to many weed species (Barnes et al., 1987).

Most studies of allelochemical weed suppression have been conducted in laboratories, greenhouses, or growth chambers. Many researchers acknowledge that the quantity of allelochemicals produced and the suppression cur under field conditions. The effects of microorganisms, plant stress, weather, insect herbivory, growth stage, soil nutrient levels, etc. may all have a role in allelochemical production (Einhellig, 1987), and these influences may be lost or modified in a controlled environment.

When attempting to demonstrate allelopathic effects in the field, a control mulch of poplar (Populus) excelsior has been used to 
separate chemical from physical effects (Barnes and Putnam, 1983; Putnam and DeFrank, 1983). The poplar excelsior mulch was demonstrated to be inert and nontoxic to other plants (Barnes and Putnam, 1983). For example, when an equivalent mass of poplar excelsior mulch or cover crop residue of rye straw was applied to plots, differences in weed suppression were attributed to allelochemical rather than physical suppression. However, the poplar excelsior mulch is physically different from cover crop residue and may decompose at a different rate, be in closer contact with the soil surface, inhibit light penetration, and modify soil moisture and temperatures differently than cover crop residue. The validity of many field-based allelopathic studies is sometimes questioned because of their lack of an adequate control.

Mixtures of cover crop species have been used to optimize the benefits associated with their use (Creamer et al., 1992). Allelopathic suppression is a species-specific phenomenon (Hazebroek et al., 1989; Lehle et al., 1983; Overland, 1966; Purvis et al., 1985). Therefore, combining cover crop species may be a means to achieve a broader spectrum of weed control. In addition, having several allelochemicals present inhibits seed germination more than having just one present since there can be additive and synergistic effects (Einhellig, 1987).

Our study had three objectives: 1) to determine whether rye could be leached of potential allelochemicals and the leached rye used as an improved control in field studies of cover crop suppression of weeds, 2) to evaluate possible mechanisms of cover crop suppression of two weeds in a field study using cover crops leached of their allelochemicals, and 3) to determine whether cover crop mixtures suppress weeds more than individual species.

\section{Materials and Methods}

Preparation and evaluation of leached rye straw. 'Wheeler' rye was planted in the greenhouse on 17 Jan. 1992. The 5-week-old shoots were harvested on $21 \mathrm{Feb}$. and were dried at $65 \mathrm{C}$ for $48 \mathrm{~h}$. Oven-dried rye $(15 \mathrm{~g})$ was cut into $5-\mathrm{cm}$ pieces and placed in $300 \mathrm{ml}$ distilled water at $\mathrm{pH} 6$. The mixture was placed on a vigorous shaker for $24 \mathrm{~h}$ at room temperature (23C) and then vacuum-extracted through four layers of cheesecloth. The leachate was stored at $2 \mathrm{C}$. The original rye residue was resuspended in distilled water $(\mathrm{pH} 6)$ and was reextracted using the same procedure an addi-

Table 1. Percent inhibition of in vitro lettuce seed germination from rye (leached and unleached) and rye + leachate from the first $24-h$ extraction.

\begin{tabular}{lcc}
\hline \hline \multicolumn{2}{c}{ Rye } & \\
\hline Straw & Leachate & Inhibition $(\%)$ \\
\hline None & - & $0 \mathrm{a}^{\mathrm{z}}$ \\
Unleached & - & $95 \mathrm{~b}$ \\
Leached & - & $2.5 \mathrm{a}$ \\
& + & $100 \mathrm{~b}$
\end{tabular}

${ }^{2}$ Mean separation by least significant difference at $P$ $\leq 0.05$.

HortScience, Vol. 31(3), June 1996 tional three times over three consecutive 24-h periods. These extractions were conducted at $2 \mathrm{C}$ to prevent rotting of the straw, and the rye then was redried at $65 \mathrm{C}$ for $\geq 48 \mathrm{~h}$. The four extracts were centrifuged at $16,300 \times g$ for 25 min to remove particulate matter. The supernatant was collected and analyzed by highperformance liquid chromatography (HPLC) and was used in a seed germination bioassay. HPLC analysis was used to detect phenolic

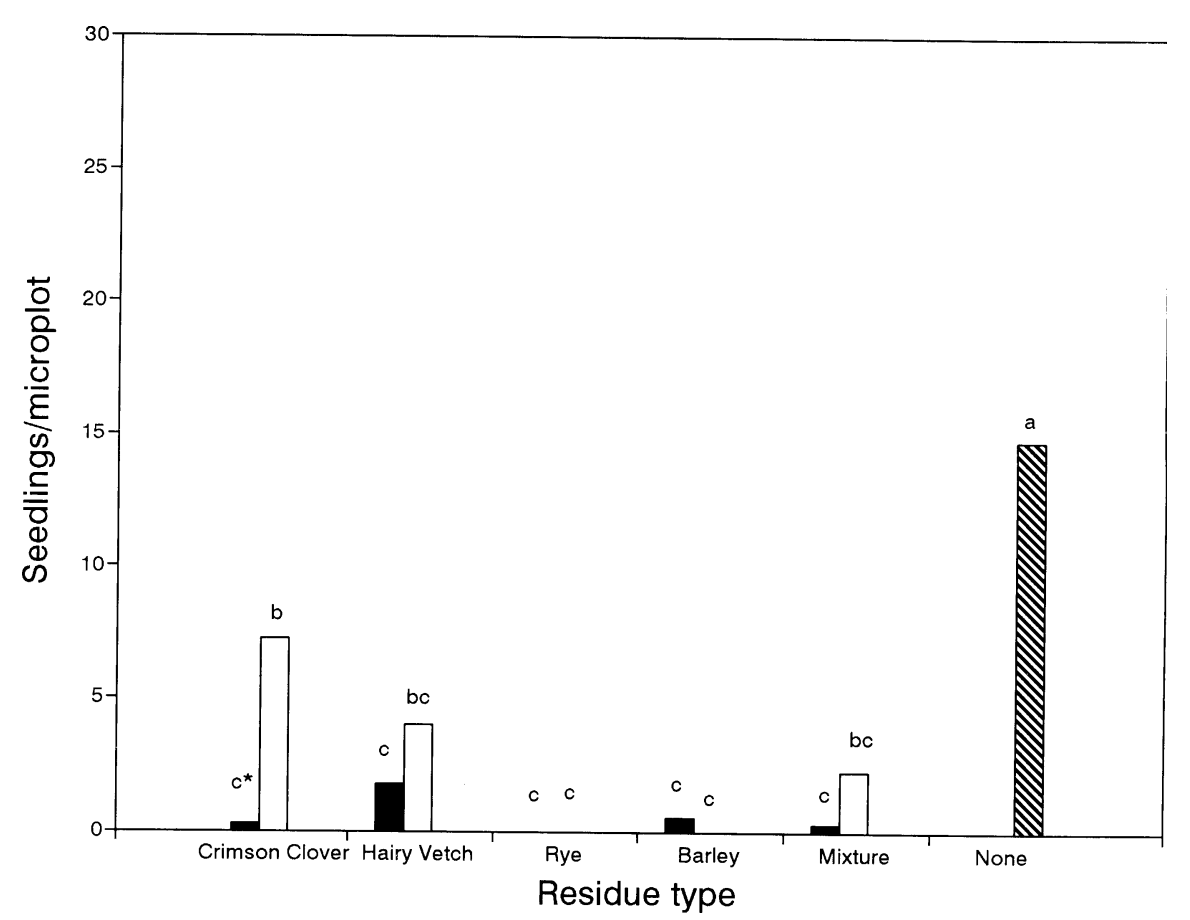

Fig. 2. Influence of $(\square)$ cover crop roots and shoots, ( $\square$ ) leached cover crop shoots, and ( $\square$ ) no cover crop on seedling emergence of eastern black nightshade 30 days after planting in Columbus, Ohio, 1993.

Least significant difference at $P \leq 0.05=6.5$.

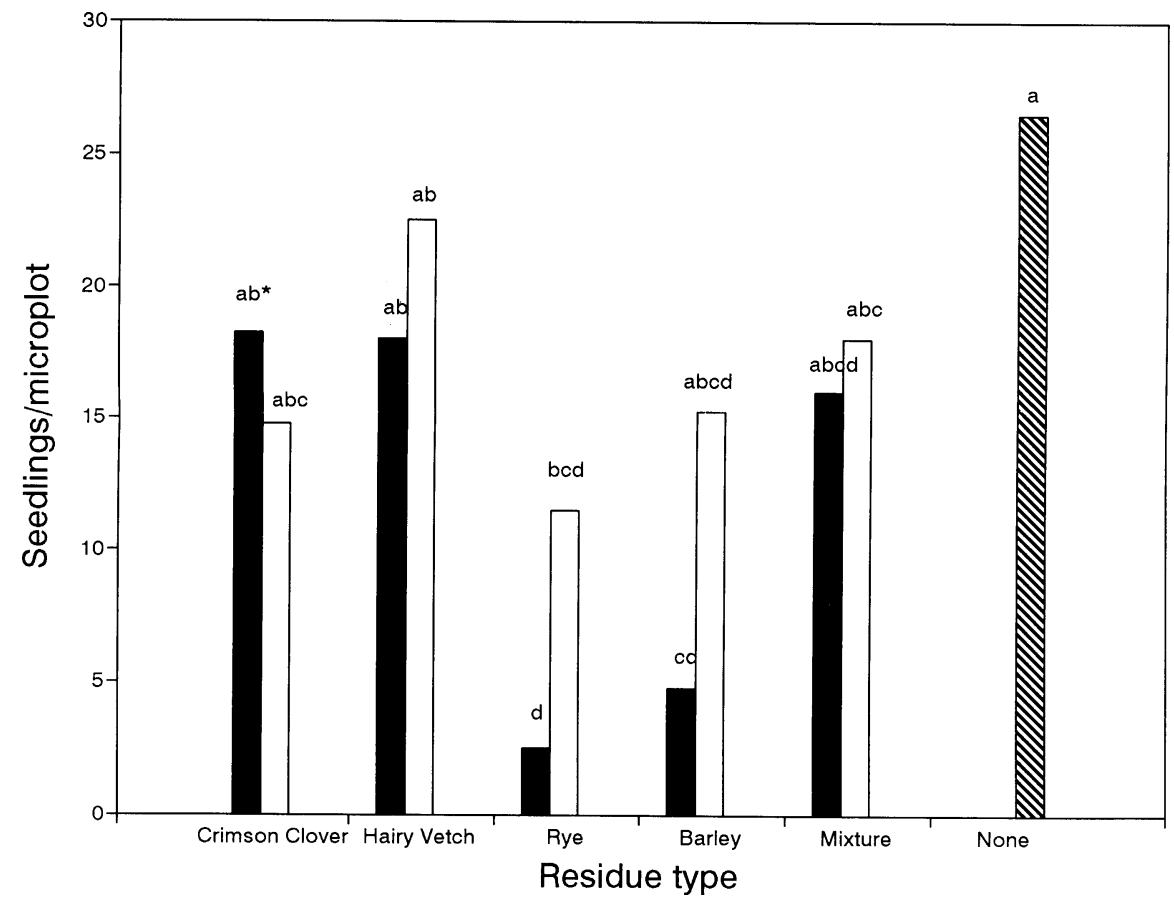

Fig. 3. Influence of $(\square)$ cover crop roots and shoots, ( $\square$ ) leached cover crop shoots, and $(\square)$ no cover crop on seedling emergence of yellow foxtail 30 days after planting in Columbus, Ohio, 1993. Least significant difference at $P \leq 0.05=13$.

compounds in the four extracts and to construct a time course of their removal from rye. Most of the allelochemicals in rye are phenolic compounds (Jain et al., 1989). Samples of 20 $\mu 1$ were analyzed with a HPLC system (Waters, Milford, Mass.) fitted with a reversedphase column (modelC-18; Alltech, Deerfield, Ill.) $(4.6 \times 250 \mathrm{~mm})$. The detector (model 481 LC spectrophotometer; Lambda-Max, Milford, Mass.) was set at $280 \mathrm{~nm}$. The solvents used

\section{.}


were 1) methanol and 2) water. The gradient was based on the method of Singh et al. (1989).

A seed germination bioassay was conducted to determine the effectiveness of the extraction procedure in removing allelochemicals and of the HPLC analysis in detecting potential phenolic allelochemicals in the rye extract. Lettuce seeds (Lactuca sativa 'Ithaca'), previously shown to be sensitive to rye allelochemicals (Barnes and Putnam, 1986), were used for the bioassay. Ten lettuce seeds were arranged in $100 \times 15-\mathrm{mm}$ petri dishes on top of a Whatman no. 1 filter paper. The eight treatments applied to the seeds included leached (for 4 days) or unleached rye residue, the four rye extracts, leached rye residue plus the rye extract, and a control of no rye residue or extract. The leached rye residue plus rye extract treatment consisted of rye leached for 4 days combined with the extract obtained after the first 24-h extraction period. Treatments were replicated four times.

Leached and unleached rye residue treatments included $0.33 \mathrm{~g}$ of rye straw cut into 5 $\mathrm{cm}$ pieces in each petri dish. This quantity of rye straw was chosen because it was sufficient to elicit a germination response in lettuce seeds and was equivalent to a field rate of rye straw at $4900 \mathrm{~kg} \cdot \mathrm{ha}^{-1}$ (Barnes et al., 1987). Leached or unleached rye residue was placed in the bottom of petri dishes and covered with filter paper. For rye extract treatments, $6.6 \mathrm{ml}$ from each extraction period was added to filter paper in petri dishes and allowed to evaporate. This volume of extract was equivalent to the volume extracted from $0.33 \mathrm{~g}$ of rye straw. Lettuce seeds were placed on top of the filter paper, and distilled water was added as needed for germination. The petri dishes were placed in a germination chamber at $25 \mathrm{C}$ for 4 days. Seeds were defined as germinated when the radicle emerged from the seedcoat.

Field studies of leached and unleached cover crop residue. In late Aug. 1992, clay drainage tiles, $25 \mathrm{~cm}$ in diameter (microplots), were set vertically into the ground so that $\approx 2.5$ $\mathrm{cm}$ of tile was above the soil surface. Soil type was a Miami silt loam (Mesic Typic Hapludaf) with a $\mathrm{pH}$ of 6.5 and organic matter content of $1.8 \%$. The upper $15 \mathrm{~cm}$ of soil in the tiles was removed and steam-sterilized to kill any weed seeds. Although soil microbial populations also were killed, we assumed that reinoculation would occur naturally over the winter. After replacing the soil, monocultures of hairy vetch, rye, barley, and crimson clover were planted on 27 Aug. at seeding rates of 44.8, 89.6, 89.6, and $22.4 \mathrm{~kg} \cdot \mathrm{ha}^{-1}$, respectively. A polyculture of hairy vetch, rye, barley, and crimson clover, selected from a previously conducted field screening study (Creamer et al., 1992), was seeded at 22.4, 26.9, 26.9, and $11.2 \mathrm{~kg} \cdot \mathrm{ha}^{-1}$ for each cover crop component, respectively. The basic treatment design consisted of 1) control plots in which no cover crop was grown and to which no cover crop residue was applied;2) plots in which no cover crop was grown and to which leached cover crop residue was applied in the spring; and 3) plots in which cover crops were grown (established in the fall), the shoots harvested in the spring, oven-dried, and immediately returned to the plots. Treatments 2 and 3 were conducted for each cover crop species and the cover crop polyculture for a total of 11 treatments. There were four replications.

Cover crop shoots were harvested from nearby field plots on 14 May 1993 and were dried $48 \mathrm{~h}$ at $65 \mathrm{C}$. Half of the cover crop shoot material was subjected to the leaching procedure described below, and half was reserved for addition to plots from which shoots were harvested. Cover crops were leached for $20 \mathrm{~h}$ in a 1700-liter tank equipped with 12 submersible pumps to agitate the water. Fresh water was circulated continuously from the top to the bottom. The cover crop residues then were redried at $65 \mathrm{C}$ for $48 \mathrm{~h}$.

On 25 May, half of each microplot was seeded with eastern black nightshade (EBN) and the other half with yellow foxtail. Based on previous germination tests, enough seed was planted in each microplot to average 25 viable seeds of each species per microplot. On the same day, the dried leached and unleached cover crop residues were returned to the appropriate microplots. The amount of residue added to each microplot was based on cover crop biomass achieved in a nearby study the same year. Hairy vetch, rye, barley, crimson clover, and the mixture were added to microplots at 30.3, 30.0, 20.2, 15.2, and 40.0 $\mathrm{g}$, respectively, which corresponded to biomass rates of $6175,6110,4120,3102$, and $8160 \mathrm{~kg} \cdot \mathrm{ha}^{-1}$, respectively.

Seedlings were counted after the two weeds had emerged through the residue on 10, 17, and 23 June. Aboveground weed biomass was harvested on 12 July, dried for $48 \mathrm{~h}$ at $65 \mathrm{C}$, and weighed to determine dry weights. Laboratory and field data were subjected to analysis of variance, and least significant difference tests were used to separate means (Wilkinson, 1990).

\section{Results and Discussion}

Evaluation ofleached rye straw. The HPLC analysis of aqueous extractions of greenhousegrown rye straw showed one major peak detected at $280 \mathrm{~nm}$ after $\approx 3$ min of the 30 -min run for the first 24-h extraction (data not shown). Each successive extraction demonstrated a progressively smaller peak, with the fourth extraction showing a very small peak (Fig. 1), indicating a decrease in soluble compounds leached from rye straw with successive extractions. Results from the seed germination bioassay showed a consistent response, with percent germination inhibition being $100 \%$ with the first extraction and decreasing with successive extractions to $0 \%$ (Fig. 1). Lettuce germination was inhibited by the unleached rye straw and the leached rye with the leachate from the initial extraction added back but not by the leached rye straw (Table 1).

These results demonstrated that allelochemicals were leached from rye residue and that the leached shoot residue can be used as a control to separate the physical effects of weed suppression of surface rye mulch from other types of interference.

Field studies of leached and unleached cover crop residue. Leached cover crop shoot residues of all five cover crops reduced EBN emergence compared to the control treatment, indicating a physical suppression component in overall cover crop suppression of this weed (Fig. 2). Leached crimson clover and hairy vetch inhibited emergence of EBN 54\% and $75 \%$, respectively, 30 days after planting (DAP). Leached rye, barley, and the mixture

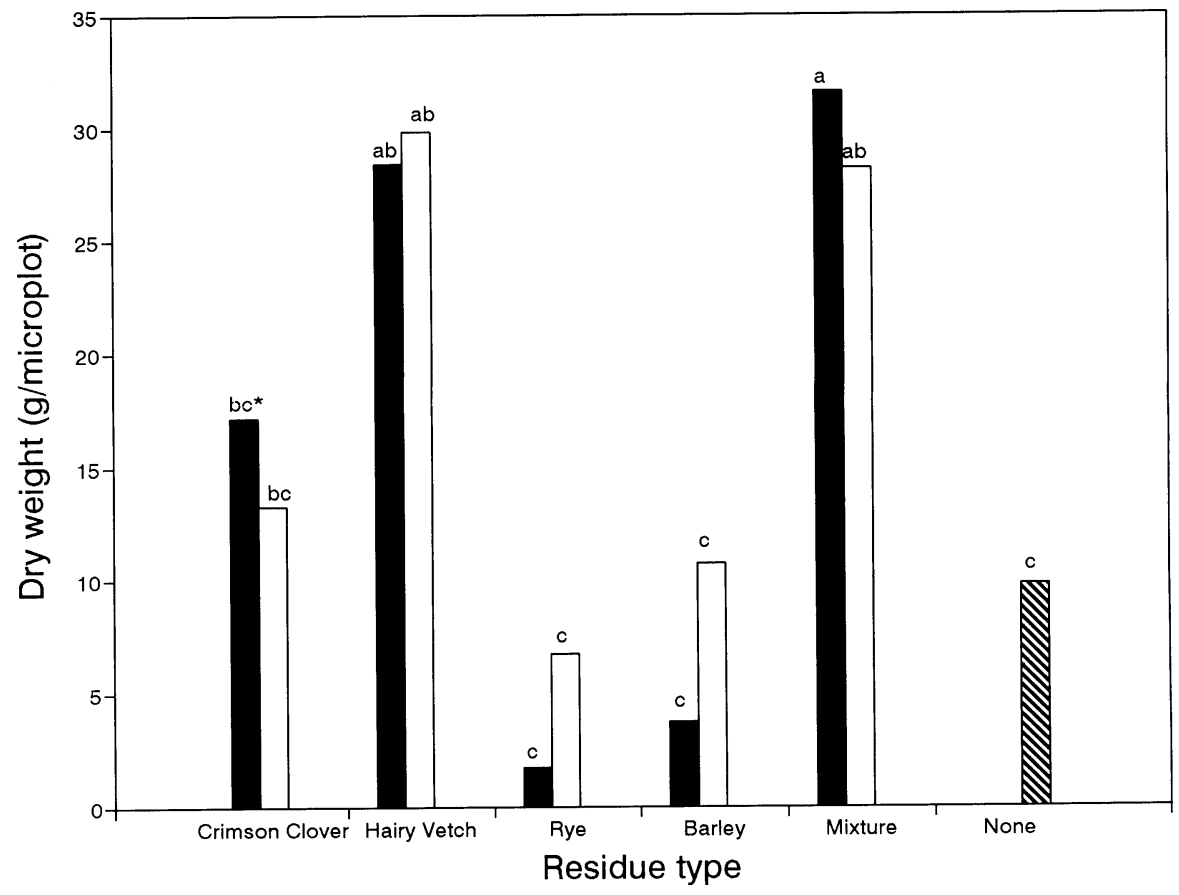

Fig. 4. Influence of ( $\square$ ) cover crop roots and shoots, $(\square)$ leached cover crop shoots, and ( $\square$ ) no cover crop on aboveground biomass of yellow foxtail 48 days after planting in Columbus, Ohio, 1993. Least significant difference at $P \leq 0.05=17.3$. 
inhibited emergence $\approx 98 \%$. Data from 16 and 23 DAP are not shown because they were similar to the last sample date. EBN is small seeded; thus, the suppression was probably due to the sensitivity of the EBN seed to light exclusion. Physical effects of the crimson clover residue accounted for only a portion of the EBN suppression by cover crop roots and unleached shoots, suggesting additional suppression by allelopathy or other components of interference. Crimson clover roots and shoots suppressed EBN emergence 100\% compared to the no-mulch control. Aboveground EBN dry weights showed no differences in response to treatments (data not shown) and were low in all plots because little growth had taken place by harvest.

Plots with roots and unleached shoots of rye and barley suppressed yellow foxtail emergence $90 \%$ and $81 \%$, respectively (Fig. 3). The suppression by rye can be attributed to physical suppression alone. For barley, the physical suppression alone was not enough to reduce emergence, but when combined with the allelochemicals in the roots and shoots, suppression occurred. Other studies have shown that grasses are not suppressed by allelochemicals as much as broadleaf weeds (Barnes et al., 1986; Weston et al., 1989). Yellow foxtail dry weights were higher in hairy vetch and the mixture compared to rye, barley, and the control (Fig. 4). In a related study the same year, the percent $\mathrm{N}$ in the aboveground biomass of hairy vetch, rye, barley, crimson clover, and the mixture was $3.4 \%$, $1.26 \%, 1.51 \%, 1.93 \%$, and $2.5 \%$, respectively. Based on the material added to each microplot, $\mathrm{N}$ in the aboveground biomass would total 209, 77, 62, 59, and $204 \mathrm{~kg} \cdot \mathrm{ha}^{-1}$, respectively. Weeds, such as yellow foxtail, likely can readily use the additional $\mathrm{N}$ released by the hairy vetch and the mixture, which may be one reason that the dry weights of the yellow foxtail in those treatments were higher than those in the rye, barley, and control microplots. In this study, the suppression affected density, but weeds that did emerge grew easily and two weeds in one microplot accumulated as much biomass as 10 weeds in another.
The technique described here for separating physical effects from other interference components in the suppression of weeds holds promise. While we recognize that allelochemicals can come from roots and shoots, there was no attempt in this study to determine the source of interference. Future studies need to address this aspect. Our results support previous work showing that cover crop weed suppression is species specific but also indicates that growing a mixture of cover crops will not necessarily lead to a broader spectrum of weed control. Future studies using larger plots with a wider variety of weed species could answer this question. Our results demonstrate that EBN emergence (and possibly that of other small, light-sensitive weed seedlings) can be physically suppressed independent of allelochemical mechanisms, which supports the general practice of using cover crops as weed-suppressing mulches. Our study also suggests that a weed species may use $\mathrm{N}$ released by cover crop residues, and this response should be considered in the selection and management of cover crop mulches.

\section{Literature Cited}

Barnes, J.P. and A.R. Putnam, 1983. Rye residues contribute weed suppression in no-tillage cropping systems. J. Chem. Ecol. 9:1045-1057.

Barnes, J.P. and A.R. Putnam. 1986. Evidence for allelopathy by residues and aqueous extracts of rye (Secale cereale). Weed Sci. 86:384-390.

Barnes, J.P., A.R. Putnam, and B.A. Burke. 1987 Isolation and characterization of allelochemicals in rye (Secale cereale L.) shoot tissue. Phytochemistry 5:1385-1390.

Chou, C.H. and Z.A. Patrick. 1976. Identification and phytotoxic activity of compounds produced during decomposition of corn and rye residues in soil. J. Chem. Ecol. 2:369-387.

Creamer, N.G., M.A. Bennett, and B.R. Stinner. 1992. Cover crop mixtures for vegetable production. HortScience 27:176. (Abstr.)

Einhellig, F.A. 1987. Interactions among allelochemicals and other stress factors of the plant environment, p. 343-357. In: G.R. Waller (ed.). Allelochemicals: Role in agriculture and forestry. Amer. Chem. Soc., Washington, D.C.

Flach, K.W. 1990. Low-input agriculture and soil conservation. J. Soil \& Water Conservation 45:42-44.
Hazebroek, J.P., S.A. Garrison, and T. Gianfagna. 1989. Allelopathic substances in asparagus roots: Extraction, characterization, and biological activity. J. Amer. Soc. Hort. Sci. 114:152-159.

Jain, R., M. Singh, and D.J. Dezman. 1989. Qualitative and quantitative characterization of phenolic compounds. Weed Sci. 37:302-307.

Lehle, F.R., R. Frans, and M. McClelland. 1983. Allelopathic potential of 'Hope' white lupine (Lupinus albus) herbage and herbage extracts. Weed Sci. 31:513-519.

Overland, L. 1966. The role of allelopathic substances in the "smother crop" barley. Amer. J. Bot. 53:423-432.

Purvis, C.E., R.S. Jessob, and J.V. Lovett. 1985 Selective regulation of germination and growth of annual weeds by crop residues. Weed Res. 25:415-421.

Putnam, A.R. 1988. Allelopathy: Problems and opportunities in weed management, p. 77-78. In: M.A. Altieri and M. Liebman (eds.). Weed management in agroecosystems: Ecologic approaches. CRC Press, Boca Raton, Fla.

Putnam, A.R. and J. DeFrank. 1983. Use of phytotoxic plant residues for selective weed control. Crop Prot. 2:173-181.

Rice, E.L. 1974. Allelopathy. Academic, New York Shilling, D.G., R.A. Liebl, and A.D. Worsham. 1985. Rye (Secale cereale L.) and wheat (Triticum aestivum L.) mulch: The suppression of certain broadleaved weeds and the isolation and identification of phytotoxins, p. 257-271. In: A.C. Thompson (ed.). The chemistry of allelopathy: Biochemical interactions among plants. Amer. Chem. Soc., Washington, D.C.

Singh, M., R.V. Tamma, and H.N. Nigg. 1989. HPLC identification of allelopathic compounds from Lantana camara. J. Chem. Ecol. 15:81-89.

Teasdale, J.R. 1993. Interaction of light, soil moisture, and temperature with weed suppression by hairy vetch residues. Weed Sci. 41:46-51.

Weston, L.A., R. Harmon, and S. Mueller. 1989. Allelopathic potential of sorghum-sudangrass hybrid (Sudex). J. Chem. Ecol. 15:1855-1865.

White, R.H., A.D. Worsham, and U. Blum. 1989. Allelopathic potential of legume debris. Weed Sci. 37:674-679.

Wilkinson, L. 1990. SYSTAT: The system for statistics. SYSTAT, Evanston, Ill.

Worsham, D.A. 1991. Role of cover crops in weed management and water quality, p. 141-145. In: W.L. Hargrove (ed.). Cover crops for clean water. Soil and Water Conservation Soc., Ankeny, Iowa. 